\title{
Evaluation of the InterTAK Diagnostic Score in differentiating Takotsubo syndrome from acute coronary syndrome. A single center experience
}

\author{
Judyta Samul-Jastrzębska, Marek Roik, Dominik Wretowski, Andrzej Łabyk, \\ Antonina Ślubowska, Anna Bizoń, Marzanna Paczyńska, \\ Katarzyna Kurnicka, Piotr Pruszczyk, Michał Ciurzyński
}

Department of Internal Medicine and Cardiology, Medical University of Warsaw, Poland

\begin{abstract}
Background: The aim of this study was to evaluate the usefulness of a novel clinical score - the InterTAK Diagnostic Score in differentiating Takotsubo syndrome (TTS) from acute coronary syndrome (ACS).

Methods: Medical records of 40 consecutive patients with ACS and 20 patients with TTS were managed and retrospectively analyzed at the documented center. Each patient was evaluated using the InterTAK Diagnostic Score. To illustrate the diagnostic ability of the score, a receiver operating characteristic (ROC) curve was performed.

Results: Takotsube syndrome patients were more often female compared to the ACS group (70\% vs. $27.5 \%, p=0.002)$, an emotional trigger was more prevalent among the TTS group (65\% vs. $7.5 \%$, $p<0.001)$. The area under the curve $(A U C)$ for the score was 0.885 (95\% confidence interval [CI] 0.78-0.97). Using a cut-off value of 45 points, the sum of sensitivity and specificity was the highest. However, when patients with a score of $\geq 50$ were diagnosed as TTS, $85 \%$ were diagnosed correctly. When patients with score $\leq 31$ were diagnosed as ACS, $92 \%$ were diagnosed correctly.

Conclusions: The InterTAK Diagnostic Score might help in differentiating TTS from ACSs with high sensitivity and specificity. This finding requires further investigation to confirm its clinical utility. (Cardiol J 2021; 28, 3: 416-422)
\end{abstract}

Key words: Takotsubo syndrome, broken heart syndrome, acute coronary syndrome, clinical score

\section{Introduction}

Takotsubo syndrome (TTS), also known as "broken heart syndrome" or "stress cardiomyopathy" is an acute heart failure condition characterized by a temporary wall motion abnormality of the left ventricle (LV) (hypokinesia, akinesia or dyskinesia) with no significant coronary artery obstruction responsible for ischemia [1-4]. Its clinical presentation is similar to acute coronary syndrome
(ACS). These two conditions share similar symptoms at presentation (chest pain, dyspnea), electrocardiogram (ECG) abnormalities, elevated cardiac biomarkers and comparable in-hospital mortality $[1,5-10]$. The final differential diagnosis requires invasive procedures such as coronary angiography and left ventriculography [2]. The International Takotsubo Diagnostic Criteria (InterTAK Diagnostic Criteria) can be found in the Expert Consensus Document published in "European Heart Journal"

Address for correspondence: Judyta Samul-Jastrzębska, MD, Department of Internal Medicine and Cardiology, Medical University of Warsaw, ul. Lindleya 4, 02-005 Warszawa, Poland, tel: +4822502 11 44, fax: +48 2250221 42, e-mail: judyta.samul@gmail.com

Received: 14.03.2019 Accepted: 19.08.2019

This article is available in open access under Creative Common Attribution-Non-Commercial-No Derivatives 4.0 International (CC BY-NC-ND 4.0) license, allowing to download articles and share them with others as long as they credit the authors and the publisher, but without permission to change them in any way or use them commercially. 
$[1,2]$. Since TTS was first reported in Japan in 1980 s, it has been increasingly recognized all over the world and some investigators suggest that TTS could represent $1-3 \%$ of all patients with ACS and $5-6 \%$ of female presenting with suspected ST-segment elevation myocardial infarction (STEMI) $[6,11]$. According recent data about $90 \%$ of TTS patients are women and around $80 \%$ are older than 50 years [12-16]. Recently, in order to differentiate TTS and ACS in the acute stage, before coronary angiography, the InterTAK Diagnostic Score was created [17]. It considers 7 clinical parameters and could be easily used in the emergency room. Authors of the Score postulate its high sensitivity and specificity. The maximum number of points to get is 100 . According to the creators, in the population they studied (TTS vs. ACS ratio 1:2), obtaining $\geq 50$ points allows to diagnose TTS with $95 \%$ accuracy. In turn to diagnose ACS with the same accuracy, $\leq 31$ points should be obtained.

It is important to emphasize, that the model used by InterTAK Diagnostic Score creators, does not reflect the true prevalence of TTS. The predicted probability of TTS depends on its prevalence in clinical practice. Thus, in real-life, correction must be made.

The aim of our study was to evaluate the usefulness of the InterTAK Diagnostic Score in differentiating TTS from ACS among patients hospitalized in reference cardiological department.

\section{Methods}

We analyzed retrospectively the medical records of 20 consecutive patients with TTS and 40 patients with ACS hospitalized in our department between 10 October 2014 and 2 October 2018. TTS was defined based on modified Mayo Clinic Diagnostic Criteria [5, 11]: 1) a transient wall motion abnormality in the LV beyond a single epicardial coronary artery distribution; 2) the absence of obstructive coronary artery disease or angiographic evidence of acute plaque rupture, which can explain the wall motion abnormality; 3) new electrocardiographic abnormalities or elevation in cardiac troponin values; and 4) the absence of myocarditis. We considered the history of possible emotional or physical trigger. Patients with pacemaker rhythm were excluded from the study. Each patient was assigned points based on the InterTAK Diagnostic Score, which considers the following criteria: female sex (25 points), emotional (24 points) or physical trigger (13 points), absence of ST-segment depression (12 points), psychi-
Table 1. InterTAK Diagnostic Score.

\begin{tabular}{lc}
\hline Criteria & Points \\
\hline Female sex & 25 \\
Emotional trigger & 24 \\
Physical trigger & 13 \\
Absence of ST-segment depression & 12 \\
Psychiatric disorders & 11 \\
Neurologic disorders & 9 \\
QTc prolongation & 6 \\
\hline
\end{tabular}

atric disorders (11 points), neurologic disorders (9 points) and QTc prolongation (6 points) (Table 1). As a control group, cohort of patients with ACS, including patients with STEMI, non-STEMI, or unstable angina, was selected. ACS was diagnosed follow European Society of Cardiology recommendations $[18,19]$. Data of patient's clinical profile were collected. This included: demographics, vital signs, cardiovascular risk factors, comorbidities, laboratory markers, results of electrocardiography, echocardiography and coronary angiography. High sensitive troponin $\mathrm{T}$ was assayed at admission and measured using an automated quantitative electrochemiluminescence immunoassay (Roche Elecsys, Mannheim, Germany).

\section{Statistical analysis}

The categorical variables were summarized with the frequency of occurrence in each group as well as its percentage. The continuous variables were summarized with mean value and standard deviation. The differences between groups were assessed with the Fisher exact test for categorical variables and with the Student t-test for continuous ones. Assessment of each variable included in the InterTAK scale was performed with univariate logistic regression. Optimal cut-off value for our cohort in the InterTAK scale was selected based on analysis of reciver-operator curve (ROC). All tests were two-sided and the differences were considered statistically significant if the $\mathrm{p}$-values were $<0.05$. No correction was applied for multiple statistical testing. All analyses were done in the $\mathrm{R}$ language environment (version 3.5.1).

\section{Results}

Medical records of 20 TTS and 40 ACS consecutive patients were analyzed. Baseline characteristics of these two cohorts are shown in Table 2. TTS patients were more often female compared 
Table 2. Baseline Takotsubo syndrome (TTS) and acute coronary syndrome (ACS) patient characteristics.

\begin{tabular}{|c|c|c|c|}
\hline Parameter & TTS, $n=20(100 \%)$ & ACS, $n=40(100 \%)$ & $\mathbf{P}$ \\
\hline Female sex & $14(70 \%)$ & $11(27.5 \%)$ & 0.002 \\
\hline Age [years] & $72.4 \pm 12.99$ & $72.9 \pm 14.31$ & 0.893 \\
\hline \multicolumn{4}{|c|}{ Triggering factors and symptoms of admission: } \\
\hline Emotional trigger & $13(65 \%)$ & $3(7.5 \%)$ & 0.000 \\
\hline Physical trigger & $7(35 \%)$ & $9(22.5 \%)$ & 0.360 \\
\hline Chest pain & $11(55 \%)$ & $22(55 \%)$ & 1.000 \\
\hline Dyspnea & $6(30 \%)$ & $14(35 \%)$ & 0.777 \\
\hline \multicolumn{4}{|l|}{ Vital signs: } \\
\hline Heart rate $[\mathrm{bpm}]$ & $79.76 \pm 18.91$ & $77.12 \pm 19.20$ & 0.635 \\
\hline Systolic BP [mmHg] & $131.80 \pm 22.06$ & $129.85 \pm 24.05$ & 0.778 \\
\hline Diastolic BP [mmHg] & $69.87 \pm 9.43$ & $72.53 \pm 13.39$ & 0.415 \\
\hline \multicolumn{4}{|l|}{ Laboratory tests: } \\
\hline hs-TnT [ng/mL] & $0.21(0.090-0.460)$ & $0.15(0.070-0.427)$ & 0.500 \\
\hline $\mathrm{CRP}[\mathrm{mg} / \mathrm{L}]$ & $23.38(4.28-57.20)$ & $7.48(1.91-42.95)$ & 0.546 \\
\hline WBC $\left[10^{3} / \mu \mathrm{L}\right]$ & $9.12(7.25-11.25)$ & $9.35(7.03-11.19)$ & 0.753 \\
\hline \multicolumn{4}{|l|}{ ECG on admission: } \\
\hline Sinus rhythm & $18(90 \%)$ & $33(82.5 \%)$ & 0.704 \\
\hline Atrial fibrillation & $2(10 \%)$ & $6(15 \%)$ & 0.707 \\
\hline ST elevation & $3(15 \%)$ & $15(37.5 \%)$ & 0.084 \\
\hline ST depression & $3(15 \%)$ & $8(20 \%)$ & 0.736 \\
\hline Left bundle branch block & $1(5 \%)$ & $1(5 \%)$ & 1.000 \\
\hline QTc prolongation* & $2(10 \%)$ & $0(0 \%)$ & 0.999 \\
\hline \multicolumn{4}{|l|}{ TTE parameters: } \\
\hline Ejection fraction [\%] & $40.9 \pm 11.32$ & $46.52 \pm 12.52$ & 0.087 \\
\hline LVDd [mm] & $43.5 \pm 6.79$ & $46.37 \pm 6.06$ & 0.122 \\
\hline LA [mm] & $36.05 \pm 5.45$ & $37.87 \pm 5.30$ & 0.230 \\
\hline \multicolumn{4}{|l|}{ Types of TTS: } \\
\hline Apical type & $15(75 \%)$ & & \\
\hline Midventricular type & $5(25 \%)$ & & \\
\hline Basal type & 0 & & \\
\hline Focal type & 0 & & \\
\hline \multicolumn{4}{|l|}{ Type of ACS: } \\
\hline STEMI & & $13(32.5 \%)$ & \\
\hline NSTEMI & & $26(65 \%)$ & \\
\hline Unstable angina & & $1(2.5 \%)$ & \\
\hline \multicolumn{4}{|l|}{ Co-morbidities: } \\
\hline Hypertension & $11(55 \%)$ & $30(75 \%)$ & 0.146 \\
\hline Diabetes mellitus & $4(20 \%)$ & $16(40 \%)$ & 0.154 \\
\hline Hypercholesterolemia & $10(50 \%)$ & $23(57.5 \%)$ & 0.596 \\
\hline COPD or asthma & $1(5 \%)$ & $6(15 \%)$ & 0.407 \\
\hline Smoking & $4(20 \%)$ & $18(45 \%)$ & 0.088 \\
\hline Cancer & $4(20 \%)$ & $3(7.5 \%)$ & 0.208 \\
\hline Neurologic disorders & $1(5 \%)$ & $7(17.5 \%)$ & 0.249 \\
\hline Psychiatric disorders & $4(20 \%)$ & $7(17.5 \%)$ & 1.000 \\
\hline
\end{tabular}

Data are shown as number (percentage), mean \pm standard deviation or median (interquartile range). ${ }^{*} \mathrm{QTc} \geq 440 \mathrm{~ms}$ and $\geq 460 \mathrm{~ms}$ for male and female sex, respectively. BP — blood pressure; COPD — chronic obstructive pulmonary disease; CRP - C-reactvie protein; ECG electrocardiogram; hs-TnT — high sensitive troponin T; LA — left atrium diameter; LVDd — left ventricular end-diastolic dimension; NSTEMI - non-ST-segment elevation myocardial infarction; QTc - QT interval corrected for heart rate; STEMI - ST-segment elevation myocardial infarction; TTE — transthoracic echocardiogram; WBC — white blood cell count 


\begin{tabular}{|c|c|c|c|}
\hline Criteria & OR & $95 \% \mathrm{CI}$ & $P$ value \\
\hline Female sex & 6.15 & 1.89-20.05 & 0.003 \\
\hline Emotional trigger & 22.9 & 5.15-101.92 & $<0.001$ \\
\hline Physical trigger & 1.85 & $0.57-6.04$ & 0.305 \\
\hline Absence of ST-segment depression & 1.42 & $0.33-6.05$ & 0.638 \\
\hline Phychiatric disoreder & 1.18 & $0.3-4.62$ & 0.814 \\
\hline Neurologic disoreder & 0.25 & $0.03-2.17$ & 0.208 \\
\hline QTc prolongation & & $0-\operatorname{lnf}$ & 0.992 \\
\hline
\end{tabular}

Figure 1. Clinical predictors for the diagnosis of Takotsubo syndrome - variables included in the InterTAK scale. Univariate logistic regression analysis; $\mathrm{Cl}$ — confidence interval; Inf — infinity; OR — odds ratio.

to ACS group (70\% in TTS vs. $27.5 \%$ in ACS, $\mathrm{p}=0.002$ ) and the emotional trigger was more prevalent in this group (65\% vs. $7.5 \%, \mathrm{p}<0.001)$. No significant differences were found in the frequency of physical trigger. The mean value of heart rate and blood pressure at the time of admission were similar in both groups. There were no significant differences between TTS and ACS patients in mean serum troponin levels, C-reactive protein levels and white blood cell count. The analysis of electrocardiogram did not reveal any differences between groups. QTc prolongation was observed in only 2 patients with TTS.

In echocardiography examination no differences were found between the mean value of ejection fraction, LV end-diastolic diameter as well as left atrium diameter in the long axis view.

The incidence of hypertension, diabetes mellitus, hypercholesterolemia, smoking, chronic obstructive pulmonary disease, neoplasm were the same in both groups.

In univariate logistic regression each assessment was performed with each variable included in the InterTAK scale. Assessment of each variable can be seen in Figure 1.

The area under the curve (AUC) for the score was 0.885 (95\% confidence interval [CI] 0.78-0.97), using a cut off value of 45 points the score of sensitivity was $75 \%$ and specificity $95 \%$ for TTS (Fig. 2). When patients with a score of $\geq 50$ were diagnosed as TTS, 85\% were diagnosed correctly. When patients with score $\leq 31$ were diagnosed as
ACS, $92 \%$ of patients were diagnosed correctly. The relation between InterTAK score values and predicted probability of TTS in the cohort analyzed is shown in Figure 3.

\section{Discussion}

Takotsubo syndrome patients have morbidity and mortality rates that are comparable to those of ACS [5, 20-22]. TTS has long been considered a benign disorder. However, in recent years it has been revealed that TTS can be associated with life threatening complications including cardiogenic shock and ventricular arrhythmias [2,23]. Gili et al. [24] analyzed data from 2,098 TTS patients. Cardiac arrest occurred in $5.9 \%$ of them. Although TTS was first described more than 30 years ago, there are still no simple clinical criteria to allow distinguishing TTS from ACS. The most common TTS symptoms are acute chest pain, dyspnea and syncope. Moreover, new electrocardiography changes, elevation of cardiac biomarkers and LV wall motion abnormalities can be observed. Therefore, initially it is difficult to differentiate TTS patients from ACS patients. The first diagnostic criteria for TTS was introduced in 2003 by Abe et al. [25]. Since then, many documents struggling to address this issue have been created. One of the latest is the InterTAK Diagnostic Score, developed by investigators from Switzerland [17]. The InterTAK Diagnostic Score is comprised of 7 clinical parameters that can be easily obtained 


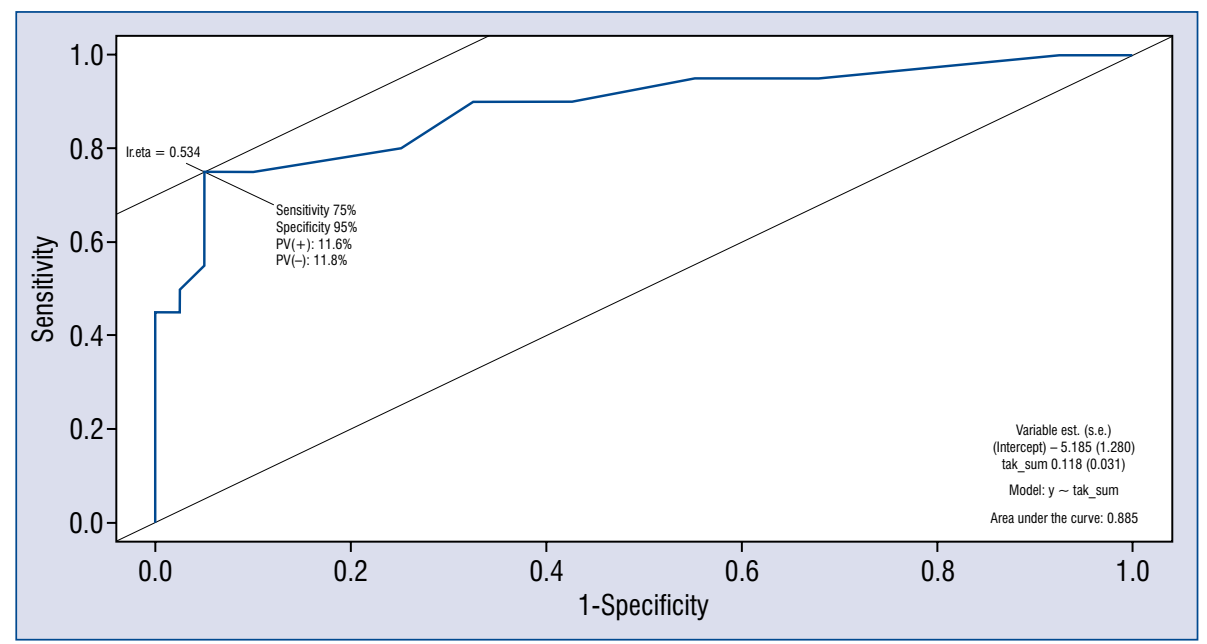

Figure 2. Receiver operating characteristic curve demonstrating area under curve and cut-off point; $P V(+)-$ positive predictive value; $\mathrm{PV}(-)-$ negative predictive value.

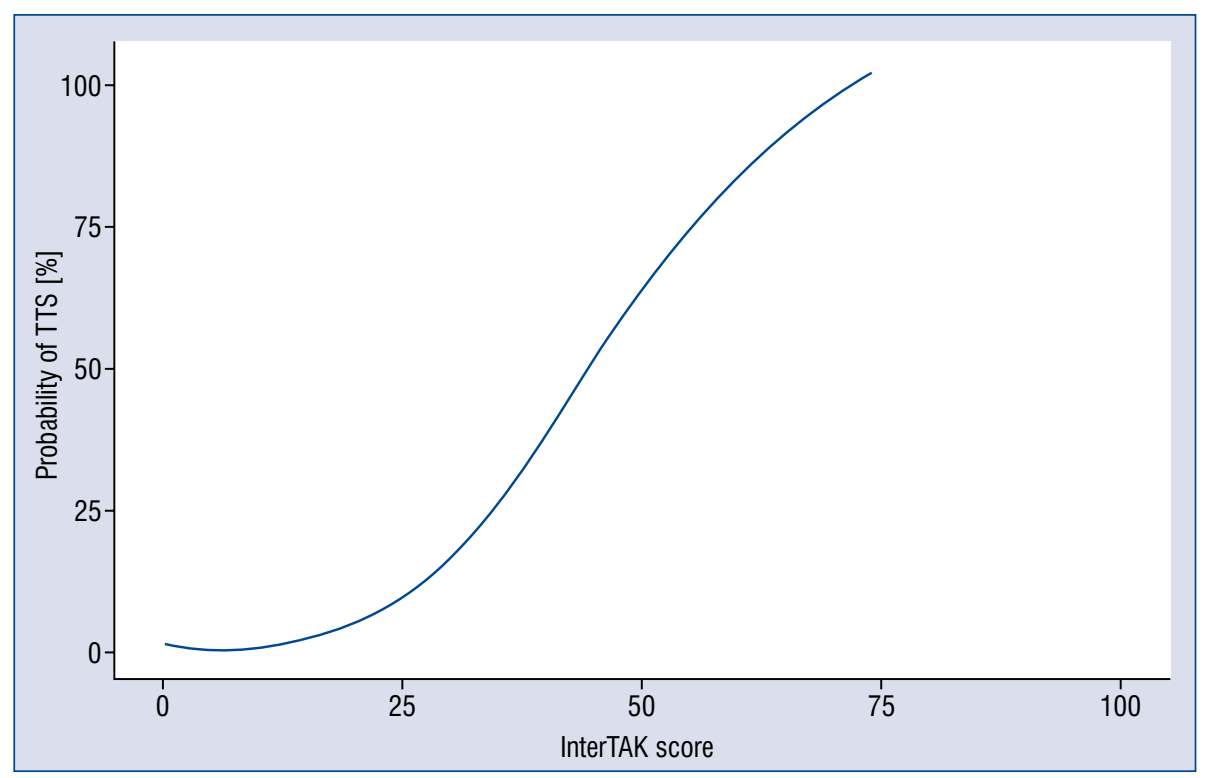

Figure 3. Relation between InterTAK score values and predicted probability of Takotsubo syndrome (TTS) in derivation cohort in the Department of Internal Medicine and Cardiology Medical University of Warsaw.

in an emergency department and do not require an imaging modality. This Score found its place in the algorithm for TTS in the International Expert Consensus Document on Takotsubo Syndrome from 2018. According to an Expert Committee, the InterTAK Diagnostic Score should be considered in symptomatic patients with no ST-segment elevation $[1,2]$. In the present study, the usefulness of the InterTAK Diagnostic Score in differentiating TTS from ACS was evaluated among patients hospitalized in the Medical University of Warsaw Clinic in Poland. The score boasts high sensitivity and specificity - these results seem to confirm this thesis. In clinical practice, TTS is not a common condition. The study group size was limited and, due to this fact, calculations were hence affected. TTS mainly affects women in post-menopausal age. Women older than 55 years have an almost 5 -fold increase in risk of developing TTS compared to those younger than 55 years $[13,14]$. In the current study, $70 \%$ of TTS patients were women with a mean age of $72.4 \pm 12.99$ years. Psychological triggers represent a range of traumatic emotions [20]. However, emotional triggers are not always 
negative, as positive emotional events can also provoke TTS. This entity has been described as the "happy heart syndrome" [26]. In the present TTS patients, all psychological triggers were negative and were present in $65 \%$ of the group. This however, did not achieve statistical significance for most of the parameters analyzed, but for the female sex and emotional triggers the p-value was $<0.05$. These are the two criteria which gained the most points scored in the InterTAK Diagnostic Score.

The AUC for the score was 0.885 , which confirms good accuracy of the test. For a cut-off value of 45 points the sum of sensitivity and specificity of the test for the group analyzed was the highest, which is close to the result obtained by investigators from Zurich: AUC $=0.971$ (95\% CI 0.96-0.98) in a derivation cohort and AUC $=0.901(95 \% \mathrm{CI}$ 0.87-0.93) in an independent validation cohort [17]. It is worth mentioning that, when using the InterTAK Score in clinical practice, the real prevalence of TTS must be considered. The current study was based on the model of the one presented by Swiss investigators, and does not reflect a true prevalence of TTS. According to the authors, correction for this bias revealed that a given score value relates to a lower corresponding probability of TTS, but still holds a very strong association of high values with the diagnosis of TTS [17]. According to the International Expert Consensus from 2018, the value of 70 score points or more in clinical practice indicates a high probability for the presence of TTS [2]. Patients with low probability should undergo coronary angiography, while in patients with high score transthoracic echocardiography should be considered.

\section{Limitations of the study}

Some of the study limitations were mentioned in the discussion above. First, this study reported a single-center experience. Second, the present study involved retrospective data for score validation. It is obvious that a prospective approach would be more promising. Moreover, the prevalence of TTS in patients admitted to the documented department was low, which affected the sample size. This may explain the lack of statistical significance for some of the parameters analyzed which are included in the InterTAK score and limit generalizability of the present data.

\section{Conclusions}

The InterTAK Diagnostic Score might help differentiating TTS from ACSs with high sensitivity and specificity and could be a useful tool for clinicians in the initial decision-making process This finding requires further investigation to confirm its clinical utility.

\section{Conflict of interest: None declared}

\section{References}

1. Ghadri JR, Wittstein IS, Prasad A, et al. International Expert Consensus Document on Takotsubo Syndrome (Part I): Clinical Characteristics, Diagnostic Criteria, and Pathophysiology. Eur Heart J. 2018; 39(22): 2032-2046, doi: 10.1093/eurheartj/ehy076, indexed in Pubmed: 29850871.

2. Ghadri JR, Wittstein IS, Prasad A, et al. International Expert Consensus Document on Takotsubo Syndrome (Part II): Diagnostic Workup, Outcome, and Management. Eur Heart J. 2018; 39(22): 2047-2062, doi: 10.1093/eurheartj/ehy077, indexed in Pubmed: 29850820.

3. Ghadri JR, Cammann VL, Napp LC, et al. International Takotsubo (InterTAK) Registry. Differences in the Clinical Profile and Outcomes of Typical and Atypical Takotsubo Syndrome: Data From the International Takotsubo Registry. JAMA Cardiol. 2016; 1(3): 335-340, doi: 10.1001/jamacardio.2016.0225, indexed in Pubmed: 27438117.

4. Sharkey SW, Lesser JR, Maron MS, et al. Why not just call it tako-tsubo cardiomyopathy: a discussion of nomenclature. J Am Coll Cardiol. 2011; 57(13): 1496-1497, doi: 10.1016/j. jacc.2010.11.029, indexed in Pubmed: 21435521.

5. Templin C, Ghadri JR, Diekmann J, et al. Clinical Features and Outcomes of Takotsubo (Stress) Cardiomyopathy. N Engl J Med. 2015; 373(10): 929-938, doi: 10.1056/NEJMoa1406761, indexed in Pubmed: 26332547.

6. Kato K, Lyon AR, Ghadri JR, et al. Takotsubo syndrome: aetiology, presentation and treatment. Heart. 2017; 103(18): 1461-1469, doi: 10.1136/heartjnl-2016-309783, indexed in Pubmed: 28839096.

7. Di Vece D, Citro R, Cammann VL, et al. Outcomes Associated With Cardiogenic Shock in Takotsubo Syndrome. Circulation. 2019; 139(3): 413-415, doi: 10.1161/CIRCULATIONAHA.118.036164, indexed in Pubmed: 30586690.

8. Frangieh AH, Obeid S, Ghadri JR, et al. InterTAK Collaborators. ECG Criteria to Differentiate Between Takotsubo (Stress) Cardiomyopathy and Myocardial Infarction. J Am Heart Assoc. 2016; 5(6), doi: 10.1161/JAHA.116.003418, indexed in Pubmed: 27412903 .

9. Opolski G, Pawlak MM, Roik MF, et al. Clinical presentation, treatment, and long-term outcomes in patients with takotsubo cardiomyopathy. Experience of a single cardiology center. Pol Arch Med Wewn. 2010; 120(6): 231-236, indexed in Pubmed: 20567207.

10. Pawlak M, Roik M, Kochanowski J, et al. Comparison of onadmission ST-segment elevation tako-tsubo patients and myocardial infarction women: in-hospital course and long-term follow-up. Kardiol Pol. 2012; 70(3): 233-240, indexed in Pubmed: 22430401.

11. Prasad A, Lerman A, Rihal CS. Apical ballooning syndrome (Tako-Tsubo or stress cardiomyopathy): a mimic of acute myocardial infarction. Am Heart J. 2008; 155(3): 408-417, doi: 10.1016/j. ahj.2007.11.008, indexed in Pubmed: 18294473. 
12. Deshmukh A, Kumar G, Pant S, et al. Prevalence of Takotsubo cardiomyopathy in the United States. Am Heart J. 2012; 164(1): 66-71. e1, doi: 10.1016/j.ahj.2012.03.020, indexed in Pubmed: 22795284.

13. Schneider B, Athanasiadis A, Stöllberger C, et al. Gender differences in the manifestation of tako-tsubo cardiomyopathy. Int J Cardiol. 2013; 166(3): 584-588, doi: 10.1016/j.ijcard.2011.11.027, indexed in Pubmed: 22192296.

14. Roshanzamir S, Showkathali R. Takotsubo cardiomyopathy a short review. Curr Cardiol Rev. 2013; 9(3): 191-196, indexed in Pubmed: 23642025.

15. Dias A, Núñez Gil IJ, Santoro F, et al. Takotsubo syndrome: Stateof-the-art review by an expert panel - Part 1. Cardiovasc Revasc Med. 2019; 20(1): 70-79, doi: 10.1016/j.carrev.2018.11.015, indexed in Pubmed: 30528096.

16. Kochanowski J, Piatkowski R, Budnik M, et al. Biventricular takotsubo cardiomyopathy in an elderly woman with uncontrolled type 2 diabetes: the biphasic echocardiographic and clinical pattern. Acta Diabetol. 2016; 53(6): 1061-1063, doi: 10.1007/ s00592-016-0916-3, indexed in Pubmed: 27665438.

17. Ghadri JR, Cammann VL, Jurisic S, et al. A novel clinical score (InterTAK Diagnostic Score) to differentiate takotsubo syndrome from acute coronary syndrome: results from the International Takotsubo Registry. Eur J Heart Fail. 2017; 19(8): 1036-1042, doi: 10.1002/ejhf.683, indexed in Pubmed: 27928880.

18. Ibanez B, James S, Agewall S, et al. ESC Scientific Document Group. 2017 ESC Guidelines for the management of acute myocardial infarction in patients presenting with ST-segment elevation: The Task Force for the management of acute myocardial infarction in patients presenting with ST-segment elevation of the European Society of Cardiology (ESC). Eur Heart J. 2018; 39(2): 119-177, doi: 10.1093/eurheartj/ehx393, indexed in Pubmed: 28886621.

19. Roffi M, Patrono C, Collet JP, et al. 2015 ESC Guidelines for the management of acute coronary syndromes in patients present- ing without persistent ST-segment elevation: Task Force for the Management of Acute Coronary Syndromes in Patients Presenting without Persistent ST-Segment Elevation of the European Society of Cardiology (ESC). Eur Heart J. 2016; 37(3): 267-315, doi: 10.1093/eurheartj/ehv320, indexed in Pubmed: 26320110.

20. Sharkey SW, Windenburg DC, Lesser JR, et al. Natural history and expansive clinical profile of stress (tako-tsubo) cardiomyopathy. J Am Coll Cardiol. 2010; 55(4): 333-341, doi: 10.1016/j. jacc.2009.08.057, indexed in Pubmed: 20117439.

21. Ghadri JR, Kato K, Cammann VL, et al. Long-Term Prognosis of Patients With Takotsubo Syndrome. J Am Coll Cardiol. 2018; 72(8): 874-882, doi: 10.1016/j.jacc.2018.06.016, indexed in Pubmed: 30115226.

22. Dias A, Núñez Gil IJ, Santoro F, et al. Takotsubo syndrome: Stateof-the-art review by an expert panel - Part 2. Cardiovasc Revasc Med. 2019; 20(2): 153-166, doi: 10.1016/j.carrev.2018.11.016, indexed in Pubmed: 30581088.

23. Di Vece D, Citro R, Templin C, et al. Outcomes Associated With Cardiogenic Shock in Takotsubo Syndrome. Circulation. 2019; 139(3): 413-415, doi: 10.1161/CIRCULATIONAHA.118.036164, indexed in Pubmed: 30586690.

24. Gili S, Cammann VL, Schlossbauer SA, et al. Cardiac arrest in takotsubo syndrome: results from the InterTAK Registry. Eur Heart J. 2019; 40(26): 2142-2151, doi: 10.1093/eurheartj/ehz170, indexed in Pubmed: 31098611.

25. Abe Y, Kondo M, Matsuoka R, et al. Assessment of clinical features in transient left ventricular apical ballooning. J Am Coll Cardiol. 2003; 41(5): 737-742, doi: 10.1016/s0735-1097(02)02925-x, indexed in Pubmed: 12628715.

26. Ghadri JR, Sarcon A, Diekmann J, et al. InterTAK Co-investigators:. Happy heart syndrome: role of positive emotional stress in takotsubo syndrome. Eur Heart J. 2016; 37(37): 2823-2829, doi: 10.1093/eurheartj/ehv757, indexed in Pubmed: 26935270. 